\title{
Study of the multilayered nanostructure and thermal stability of PMMA/PS amorphous films
}

\author{
F. Ania ${ }^{\text {a, } *}$, F.J. Baltá-Calleja ${ }^{\text {a }}$, S. Henning ${ }^{b}$, D. Khariwala ${ }^{c}$, A. Hiltner ${ }^{c}$, E. Baer ${ }^{c}$ \\ a Instituto de Estructura de la Materia, CSIC, Serrano 119, E-28006 Madrid, Spain \\ ${ }^{\mathrm{b}}$ Department of Physics, Martin-Luther-University, Halle Wittenberg, Geusaer Str., D-06217 Merseburg, Germany \\ ${ }^{\mathrm{c}}$ Department of Macromolecular Science, Case Western Reserve University, 2100 Adelbert Road, Cleveland, OH 44106-7202, USA
}

\section{A R T I C L E I N F O}

\section{Article history:}

Received 7 November 2009

Received in revised form

5 February 2010

Accepted 12 February 2010

Available online 18 February 2010

\section{Keywords:}

Nanostructure

Amorphous polymers

Multilayers

\begin{abstract}
A B S T R A C T
The nanolayered structure of a forced-assembly of two immiscible amorphous polymers, prepared by layer-multiplying coextrusion, is analyzed for the first time by means of USAXS. The experimental long spacings for the series of PMMA/PS films studied show a good correlation with the nominal periodicity values of the stacks. In addition, the long spacings, derived from a localized area in AFM, are also in good agreement with the USAXS values averaged over much larger areas. The structural variation, after thermal treatment, of two samples with nominal periodicities of 174 and $215 \mathrm{~nm}$ is reported. In the range RT- $140{ }^{\circ} \mathrm{C}$, the nanolayered structure is mostly well preserved as evidenced by AFM. However, the absence of USAXS maxima after annealing at temperatures included in the above range has been tentatively explained by interfacial coarsening and spinodal dewetting occurring between the forcedassembled polymer layers. Above $140{ }^{\circ} \mathrm{C}$, the interfacially driven break-up of the layers ends up with the final disappearance of the multilayered structure.
\end{abstract}

(c) 2010 Elsevier Ltd. All rights reserved.

\section{Introduction}

Recent advances in layer-multiplying coextrusion of incompatible polymers have made possible to fabricate multilayered nanostructures with improved barrier, thermal and mechanical behaviour. Multilayered films are already used in industrial applications such as coating and packaging or films with unique optical properties [1-3]. In contrast with the self-assembly of block copolymers into ordered arrays [4], layer-multiplying coextrusion uses forced-assembly to create micro- or nanolayered polymer films. These multilayer films consist of a few to thousands of layers and each layer thickness can go down to the nanometer scale. Other methods to produce multilayer nanostructures at much smaller scale are: layering spin-coated films on top of each other $[5,6]$ or layer-by-layer assembly [7].

In a preceding paper [8], comparison of ultra-small-angle X-ray scattering (USAXS) and atomic force microscopy (AFM) results shed light on many details of the highly regular nanolayered structure present in coextruded poly(ethylene terephthalate)/polycarbonate (PET/PC) films. The experimental long spacings for these semicrystalline/amorphous nanolayers, derived from USAXS, showed values which correlate fairly well with the nominal periodicity values

\footnotetext{
* Corresponding author. Tel.: +34 915619400; fax: +34 915642431.

E-mail address: emfernando@iem.cfmac.csic.es (F. Ania).
}

of the stacks prepared by the coextrusion method. AFM images revealed periodicities which were also in good agreement with the USAXS data. On annealing, the multilayered architecture of the films was well preserved even at temperatures $\left(T_{\mathrm{a}} \sim 150{ }^{\circ} \mathrm{C}\right)$ higher than the glass transition temperature of both constituent polymers. At these temperatures, the USAXS patterns showed a large increment of the scattering power due to the higher electron density difference among alternating layers provoked by the crystallization of PET.

On the other hand, forced assemblies of two immiscible glassy polymers have also been obtained by the coextrusion method [9]. Even for two chemically different polymers, their interfaces are not completely sharp and, in spite of the highly unfavourable enthalpic interaction between them, a small extent of interpenetration of molecules is allowed. In this way, a new "interphase" is created whose thickness, in case of poly(methyl methacrylate)/polystyrene (PMMA/PS), has been probed to be around 5-6 nm [10,11]. As polymer layers become thinner and comparable to the size of the interphases, the bulk material may behave as an entirely new interphase material $[9,11,12]$. For such systems, it is important to understand the extent to which the nanoscale size of the layers as well as the interfaces affect the properties of both the overall material and the individual layers. Some physical properties like the glass transition temperature $T_{\mathrm{g}}$, toughness, strength at break, physical aging rate and molecular orientation may undergo significant changes as thickness decreases below the nanometre scale [13-19]. 

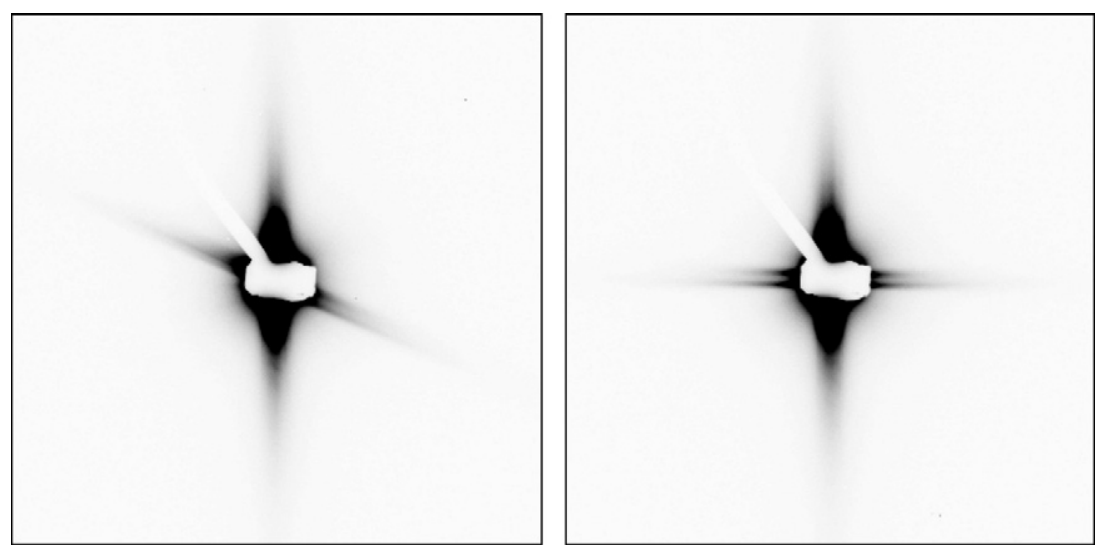

Fig. 1. USAXS patterns of a PMMA/PS (50/50) nanolayered film with nominal layer thickness of $174 \mathrm{~nm}$. a) initial pattern and b) after rotating the sample by $3^{\circ}$.

In order to characterize the nanostructure of thin films in the direction perpendicular to the surface, $\mathrm{X}$-ray reflectometry, neutron reflectometry (NR) [20] and GISAXS [21] are commonly employed. However these techniques require a high regularity of the samples together with very small surface roughness. The forced-assembly of layers by coextrusion does not fulfil such stringent requirements, but on the other hand, the ability to fabricate thousands of layers within a film permits the use of more conventional scattering methods.

The aim of the first part of the present work is to study the multilayered structure of PMMA/PS films by means of the USAXS technique. Information on the average layer thicknesses over the entire film crosssection obtained by USAXS will be compared with local average layer thicknesses as derived from selected AFM images [11]. It is worth pointing out that this is the first time that a regular structure, with well-defined large spacings up to $500 \mathrm{~nm}$, of two immiscible glassy polymers (PMMA/PS) has been investigated by means of USAXS.

A further point of interest, due to the importance that the stability of laminate structures has in industrial processes, is to follow the changes that annealing, below and above the glass transition temperatures of the constituent polymers, may produce in the forced nanolayered architecture and in the nature of the interfaces. Much work has been done regarding the dynamics and stability of extremely thin polymer films and a complete review has been published very recently [22]. For spun cast polymer films on a solid substrate, it is known that film rupture can happen mainly through two different mechanisms: heterogeneous nucleation and spinodal dewetting [23]. The term "spinodal dewetting" is used in analogy to spinodal decomposition of incompatible liquids. The

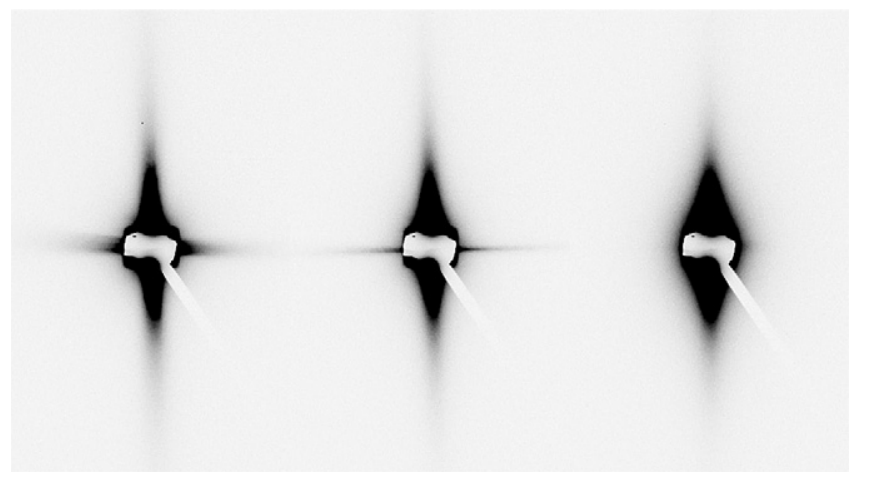

Fig. 2. Changes in the USAXS patterns of a PMMA/PS (50/50) nanolayered film with nominal layer thickness of $215 \mathrm{~nm}$. From left to right: initial unpolished sample and after increasing amounts of polishing. time scale of the heterogeneous mechanism can be many orders of magnitude smaller than that for a spinodal process and the produced instabilities become more important for relatively thick films [24]. In the particular case of a thin PS layer on a Si substrate, it has been shown that at film thicknesses of around $100 \mathrm{~nm}$, long range intermolecular forces become operative and can initiate the film rupture. The balance between these forces and the short-range repulsive forces leads to the development of dewetting patterns that highly depend on experimental conditions [23]. Such patterns can be qualitatively and quantitatively generated by means of numerical simulations [25]. The next step is the study of the phase segregation processes for a bilayer of immiscible polymers laid on top of each other. The PMMA/PS bilayer system of spun cast thin films on a Si substrate has received considerable attention due to the fact that most of the properties of both polymers are well characterized [26-29]. PMMA/PS systems have been also widely used as model system for the investigations, among others, of interfacial width measurements, block copolymer morphology, antireflection coatings, physical blendings, and reactive compatibilization [6]. The physics related to the dewetting of bilayered or multilayered systems is far more complicated than the one applying to the above mentioned liquid-solid case. The reason is that polymer-polymer interfaces can be deformable and equations governing flow must include the precise location of the interfaces.

The purpose of the second part of the paper is, thus, restricted to highlight some interesting scattering variations which take place after annealing the multilayered films at various temperatures. Such changes will be tentatively discussed in the light of similar basic mechanisms to those occurring in simpler systems.

\section{Experimental part}

\subsection{Sample preparation}

Poly(methyl methacrylate) (PMMA) was supplied by Atofina Chemicals, Inc. (Plexiglas V826). Polystyrene (PS) was provided by The Dow Chemical Company (Styron 685D). The molecular weight, determined by GPC, was 132 and $527 \mathrm{~kg} \mathrm{~mol}^{-1}$ and the density, measured with a density gradient column, was 1.1923 and $1.0450 \mathrm{~g} \mathrm{~cm}^{-3}$ respectively [11]. Films were prepared using the layer-multiplying process as described elsewhere [30]. They were fabricated into 1024 alternating layers of amorphous PMMA and PS layers (with only one exception of 4096 layers) and a volume ratio of 50/50. The nominal film thickness ranged from 25 to $300 \mu \mathrm{m}$. Some of the samples were annealed at different temperatures ranging from $75^{\circ} \mathrm{C}$ to $150{ }^{\circ} \mathrm{C}$. For this purpose, films were placed between the plates of a hot press at minimum pressure during 


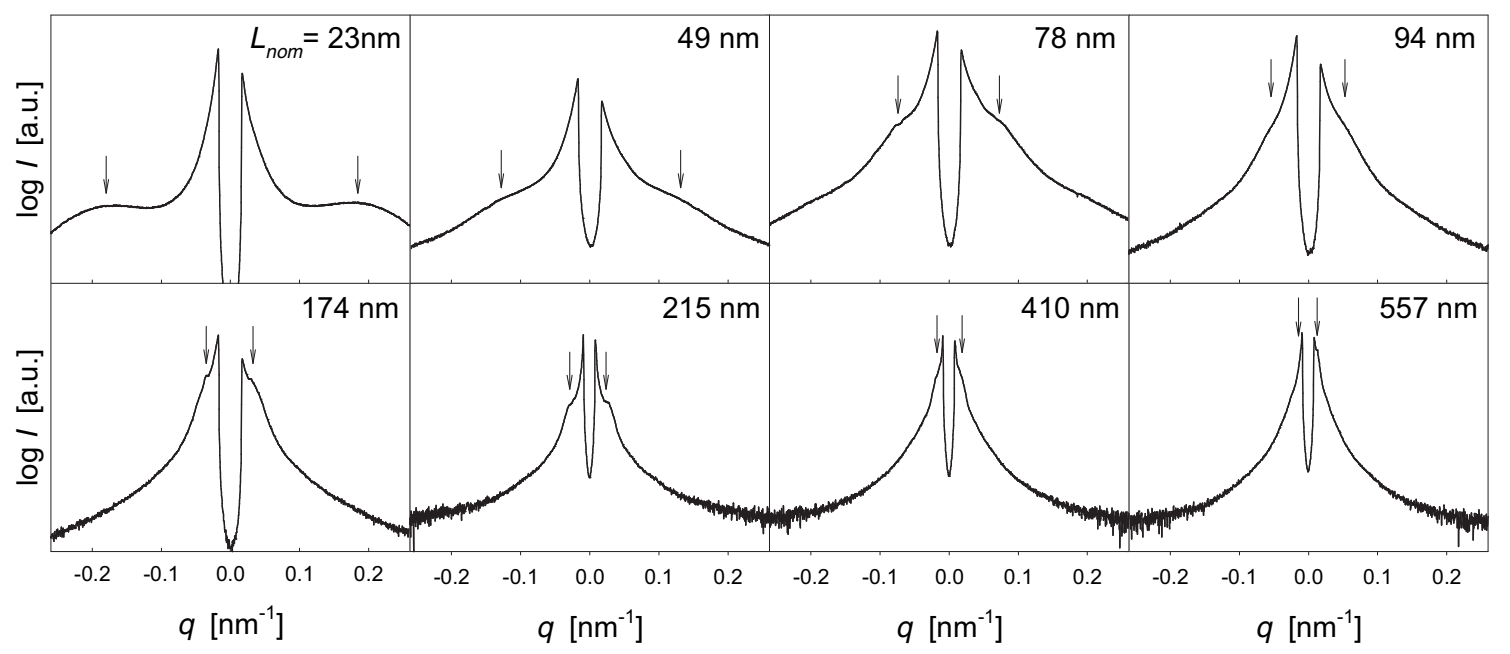

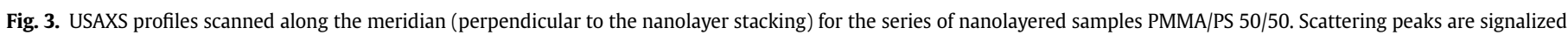
with arrows.

$30 \mathrm{~min}$ and then they were allowed to cool down to room temperature. Control unannealed samples were also studied.

As mentioned above, the PMMA/PS interfaces are very sharp with an interphase thickness of around 5-6 nm. The assemblies investigated in this study had layer repeat distances that were substantially larger than the interphase thickness.

\subsection{Techniques}

\subsubsection{USAXS}

$\mathrm{X}$-ray scattering experiments were performed at the beamline BW4 (USAXS) of the DORIS III storage ring at HASYLAB/DESY (Hamburg). The X-ray wavelength $\lambda$ was fixed to $0.138 \mathrm{~nm}$. The scattered intensity was recorded using a two-dimensional CCD camera (MARCCD 165), in $2048 \times 2048$ pixel arrays. The sample detector distance was approximately $13 \mathrm{~m}$, giving spatial resolution limits between 23 and $700 \mathrm{~nm}$. Strips cut from the polymer films,

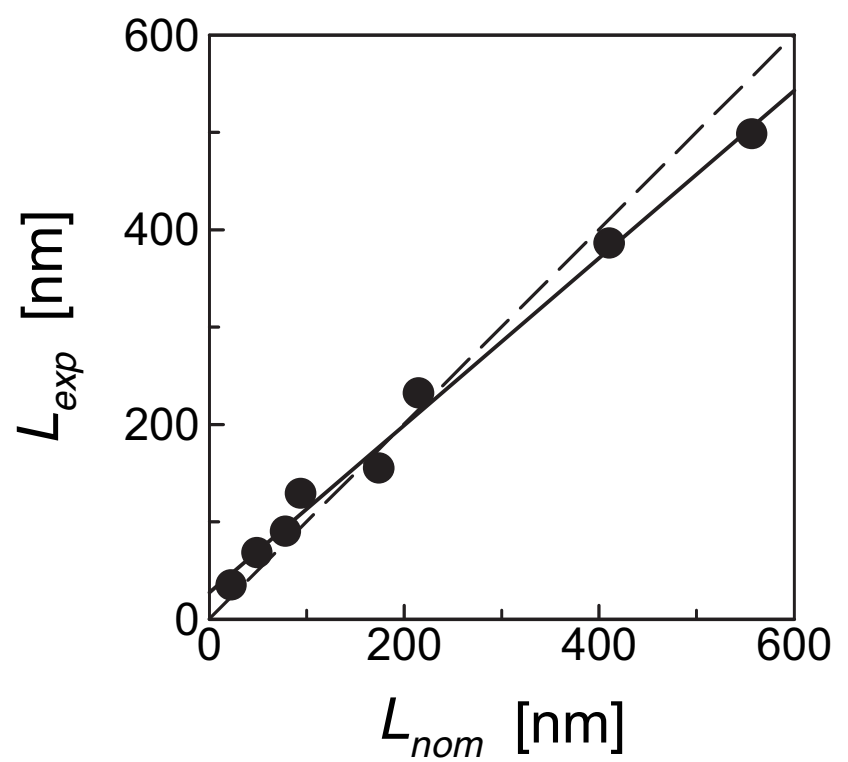

Fig. 4. Experimental USAXS long spacings $L_{\text {exp }}$ as a function of nominal values $L_{\text {nom }}$ for the PMMA/PS samples.
$2 \mathrm{~mm}$ wide, were placed with their surfaces forming an angle of about $\alpha_{\mathrm{i}}=5^{\circ}$, with the incident X-ray beam to avoid the strong grazing incidence meridional scattering [8]. Typical USAXS patterns show now a meridional scattering yielding information on the periodicity of the nanolayered structure and an apparently offequatorial scattering (Fig. 1 (left)). By carefully rotating again the sample, so that the extrusion direction becomes parallel to the Xray beam, the latter scattering reveals its true equatorial nature (Fig. 1 (right)). In addition, for thick films, as the one shown in the figure, the equatorial scattering appears horizontally-splitted. From these new observations it could be concluded that the equatorial scattering might be mainly related to the grooves produced at the sample surfaces during the extrusion process. For this reason, they are arranged parallel to the extrusion direction. Such grooves are deeper the thicker the samples are. Weak or no equatorial scattering is observed for the thinnest samples while very strong and splitted scattering appears in the thickest ones.

To test this hypothesis, against the previously suggested presence of certain electron density inhomogeneities along the extrusion direction which could be identified as aligned microvoids [8], a thick film with strong equatorial scattering was polished with a very fine silicon-carbide abrasive paper (FEPA P-4000). With increasing surface polishing, the result was the weakening of the equatorial scattering until its effective disappearance after removing the surface grooves (Fig. 2 from left to right).

\subsection{2. $A F M$}

Films were sectioned perpendicular to their surfaces with a microtome (MT6000-XL, RMC). For this purpose, film specimens were embedded in $5 \mathrm{~min}$ epoxy and cured overnight at $23^{\circ} \mathrm{C}$. Cured specimens were microtomed at $23{ }^{\circ} \mathrm{C}$ at a cutting speed of $0.5 \mathrm{~mm} \mathrm{~s}^{-1}$. The surface to be scanned by AFM was chosen from the centre of the extruded film and in the central portion of the specimen cross-section. The tapping mode of a Nanoscope IIIa (Digital Instruments) was used. It was estimated that the images from the central portion of the specimen were representative of a majority of the cross-section of the specimen. Similar images were obtained previously using standard transmission electron microscopy techniques [31]. Long spacings consisting of a pair of PS and PMMA layers were measured from AFM phase images. Statistical distribution of the long spacings was then compiled. In case of all the samples, more than 50 pairs of layers were measured. 


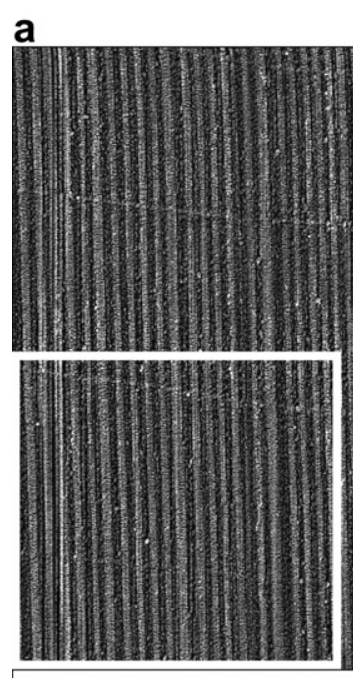

0

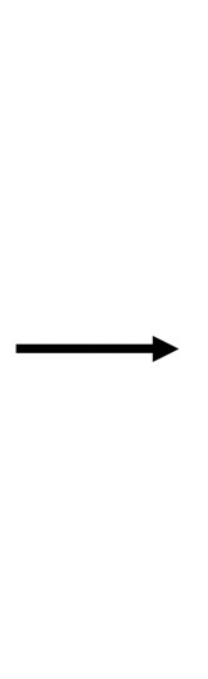

$10.0 \mu \mathrm{m}$ b

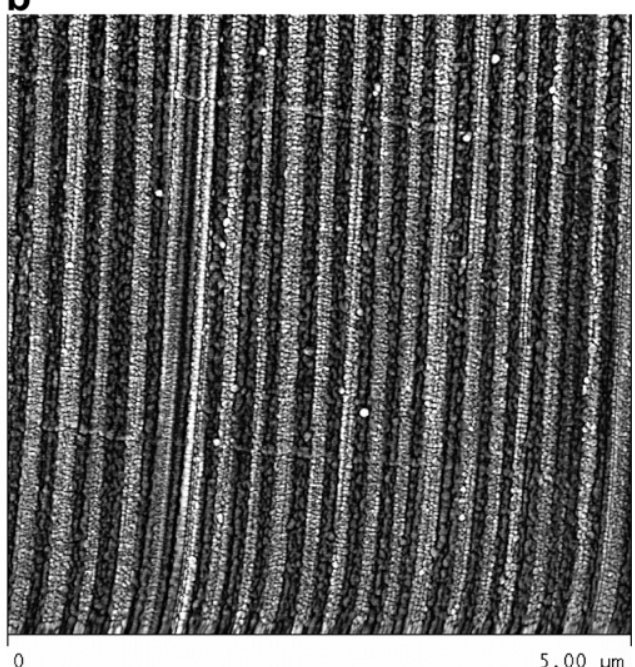

C

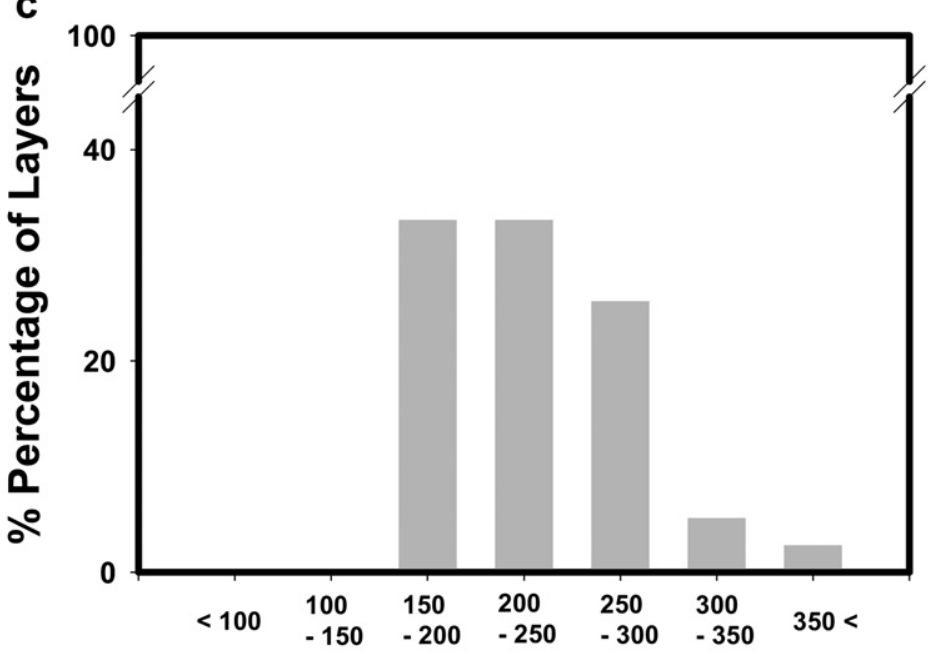

\section{Long Spacing (nm)}

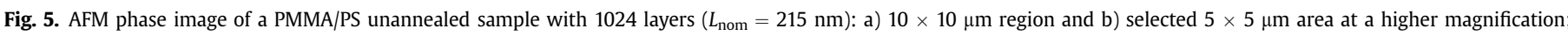
c) statistical distribution of the AFM long spacings.

\section{Results and discussion}

\subsection{Assessment of the nanolayered amorphous structure}

Fig. 3 illustrates the USAXS scans, obtained along the meridian, of the PMMA/PS 50/50 nanolayered films with nominal distances between equivalent layers, $L_{\text {nom }}$, ranging from 23 up to $557 \mathrm{~nm}$. The nominal distance is simply calculated by dividing the film thickness by half the number of layers. The scattering intensity in logarithmic scale is represented as a function of the scattering vector $q(q=2 \pi s$ and $s=2 \sin \theta / \lambda$ ). Scans were obtained by projecting into the meridian, and averaging, the intensity of 100 pixels (multiplied by $q$ ) on each side of the meridian. After correcting for the primary beam intensity and subtracting the background, the long spacings, $L_{\text {exp }}$, were derived from the angular positions of the first maximum found in the scans by simply using Bragg's law. The experimental long period represents the average distance between regions of equivalent electronic density (i.e., in case of our multilayer materials, the average distance between PMMA and PS layers).

The long spacings $L_{\text {exp }}$, derived for all the studied samples, are plotted in Fig. 4 as a function of their nominal values $L_{\text {nom. }}$. At first sight, one observes a linear relationship between the nominal and the experimental values. The regression coefficient $R^{2}$ of the linear fit is 0.9917 (continuous line in Fig. 4). However if this fit is compared with the line representing the locus of points where experimental and nominal values coincide, it reveals that the thinner long spacings tend to be larger than their corresponding nominal values, whereas the opposite behaviour is observed for the thickest layers. This result could account for a possible tendency of thinner layers to break-up and yield an average spacing value longer than expected. A similar tendency has been found for thin layers of high density poly(ethylene) (PE) coextruded between layers of poly(styrene) (PS) [32] and for PET/PC nanolayers [8].

Fig. 5(a and b) shows, as an example, an AFM phase image and the magnification of a smaller area of an unannealed sample with a nominal spacing of $215 \mathrm{~nm}$. The horizontal lines, on these and the other AFM images, are chatter marks from the microtoming. The layers were continuous although there was some nonuniformity in the layer thickness. The thickness of pairs of layers, rather than the thickness of individual layers, was measured. Hence, identifying the precise location of the interface was not required. The observed distribution of long spacings (PMMA layer plus PS layer) is shown in 

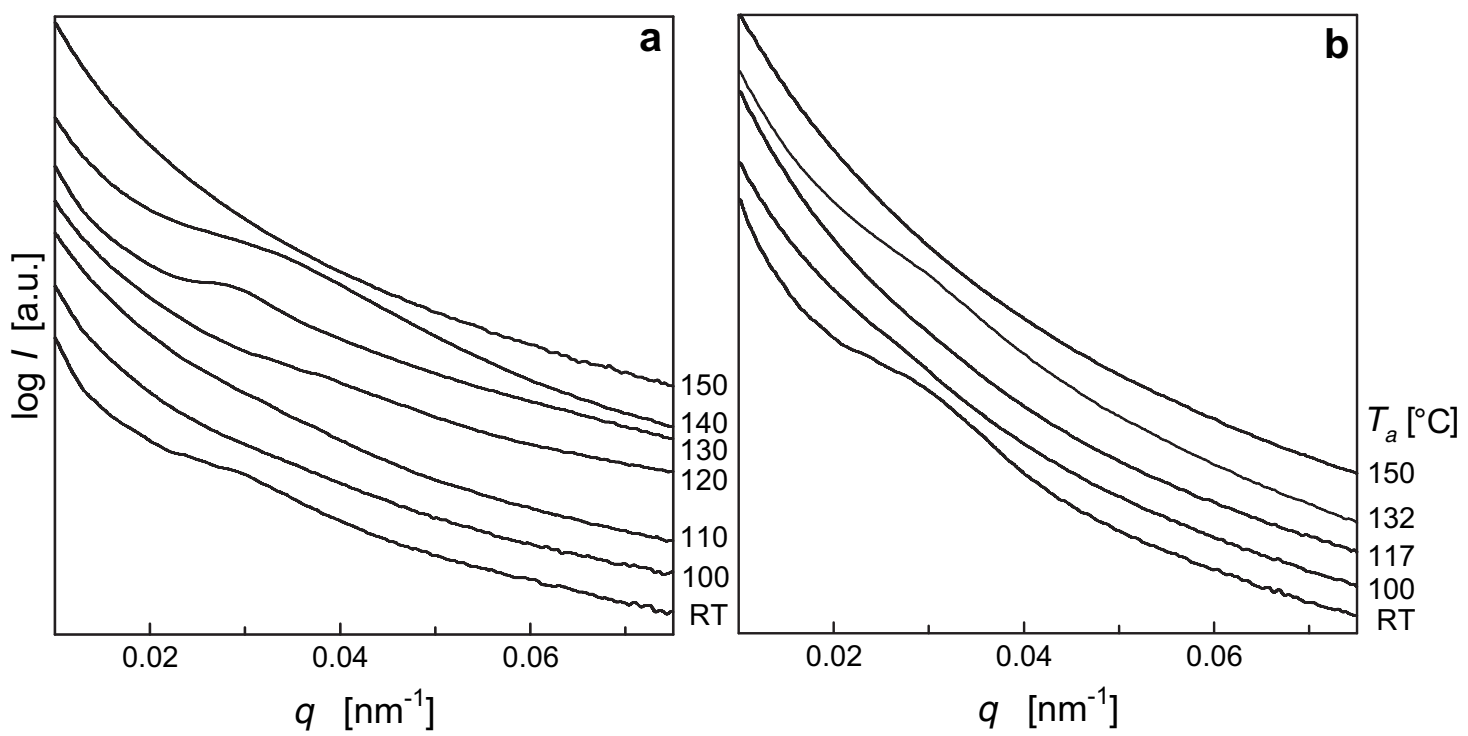

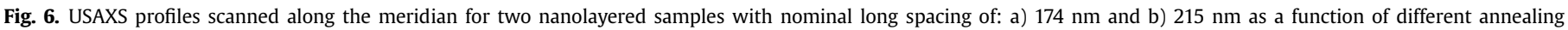
temperatures $T_{\mathrm{a}}$.

Fig. 5c. The maximum of the distribution found (244 nm) was indeed very close to the experimental SAXS long spacing $(232 \mathrm{~nm})$.

\subsection{Annealing behaviour}

Once having confirmed the highly regular nanolayered structure of the films, it is interesting to find out their thermal stability after annealing and returning to room temperature (RT). Fig. 6 illustrates the USAXS profiles scanned along the meridian for the nanolayered samples with $L_{\text {nom }}$ of a) $174 \mathrm{~nm}$ and b) $215 \mathrm{~nm}$, as a function of different annealing temperatures $T_{\mathrm{a}}$. It can be observed that the asreceived samples $\left(T_{\mathrm{a}}=\mathrm{RT}\right)$ show, in both cases, a well-defined USAXS scattering maximum. This maximum becomes much weaker after heat treatments at around $100-115{ }^{\circ} \mathrm{C}$, which is a temperature interval close to the glass transition of both polymer components $\left(T_{\mathrm{g}}(\mathrm{PMMA})=113^{\circ} \mathrm{C}\right.$ and $\left.T_{\mathrm{g}}(\mathrm{PS})=104{ }^{\circ} \mathrm{C}\right)$. The scattering peaks remain poorly defined until $130-140{ }^{\circ} \mathrm{C}$ where unexpectedly a much stronger USAXS maximum is clearly present that seems to correspond to slightly larger periodicities. Finally, annealing at still higher temperatures $\left(150^{\circ} \mathrm{C}\right)$ provokes the total disappearance of all scattering peaks. It should be mentioned that, because of these unforeseen results, the scattering experiments for the films with $L_{\text {nom }}=215 \mathrm{~nm}$ were repeated and the described behaviour was satisfactorily reproduced.

In an attempt to find out an explanation, we have followed by AFM the morphological changes occurring in the films with $L_{\text {nom }}=215 \mathrm{~nm}$ after being annealed at different temperatures. Fig. 7 ( $a$ and $b$ ) shows an AFM phase image of the sample annealed at $117{ }^{\circ} \mathrm{C}$ and a higher magnification of a smaller area of the same image, respectively. The figure reflects that layer integrity is still largely maintained in this particular area. However, looking at other regions of the material, a small amount of layer break-up can be clearly distinguished (Fig. 7c). The percent distribution of long spacings (Fig. 7d), calculated from both images, is broader and slightly shifted towards larger values (mean value: $260 \pm 80 \mathrm{~nm}$ ) as compared to the very similar distributions found for the unannealed and the $100{ }^{\circ} \mathrm{C}$ annealed samples. It is noteworthy that, even though the layers are mostly well defined for $117{ }^{\circ} \mathrm{C}$, the USAXS scattering peak is only weakly observed or not observed at all.

Surprisingly, the sample annealed at $132{ }^{\circ} \mathrm{C}$ shows by AFM a better layer morphology than the sample annealed at a lower temperature $\left(117^{\circ} \mathrm{C}\right)$. No traces of layer break-up are observed for this sample (Fig. 8a and b) and the interfaces are more sharply defined than for lower annealing temperatures, where a granular texture can be observed.

Finally, annealing at still higher temperatures $\left(150^{\circ} \mathrm{C}\right)$ provokes the total disappearance of the USAXS scattering peak in accordance with the AFM image showing that the layered morphology is completely distorted (see Fig. 9a and b).

\subsection{Discussion on the thermal stability of the films}

The first thing to be taken into account in the discussion of the results is the fact that AFM images show that the nanolayered architecture is preserved up to annealing temperatures of $130-140{ }^{\circ} \mathrm{C}$. The decrease in the USAXS scattering contrast between layers of the two polymers could be tentatively related to changes of their respective electron densities with the temperature treatment. However, considering the almost parallel thermal variation of the specific volumes of PMMA and PS [33], it is doubtful that their respective electron density values might come close enough as to minimize the scattering contrast.

An alternative explanation could come from the fact that the lack of scattering peaks is observed in a temperature range which is slightly larger than the one defined by the $T_{\mathrm{g}}$ of both polymer components. In fact the latter interval could be effectively extended at the interfaces as it has been reported that, for PMMA/PS incompatible blends, the PMMA side rigidifies in the presence of PS, while the opposite occurs in the PS side [34]. This should lead to an increase of the $T_{\mathrm{g}}$ for PMMA and a decrease for PS. The observation of some layer break-up at this point does not seem to be statistically significant and could be attributed to inhomogeneities or frozen-in internal stresses within the films that could have produced significant changes even in the glassy state [35]. One could suggest that the earlier melting of PS, at lower annealing temperatures, could provoke the appearance of an undulation at the surface of the PS layers followed, once both polymers are molten, by the anisotropic growth of small PS domains at the boundary interphase between adjacent layers. These processes, resembling an spinodal dewetting, should provoke an increased roughening of the initially sharp phase boundaries. It is known that such a smearing increases the diffuse X-ray scattering [36] which could be responsible of blurring away 
a
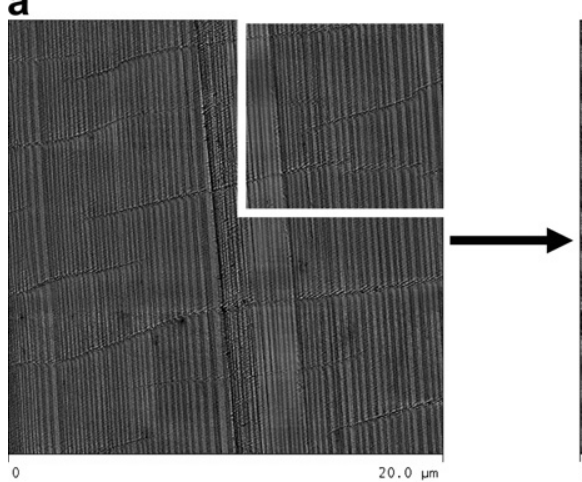

b

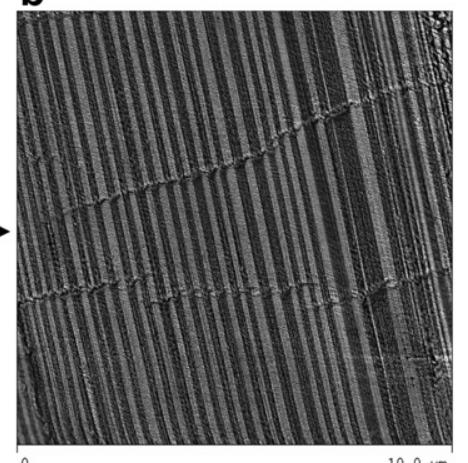

C

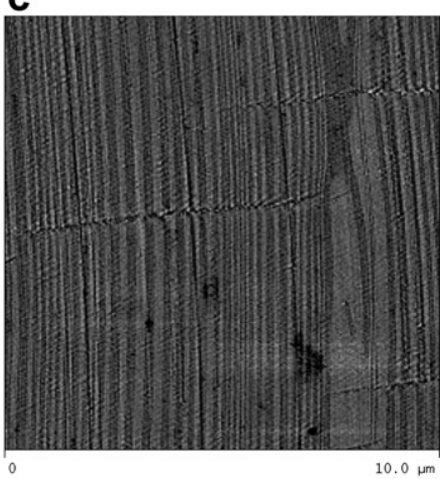

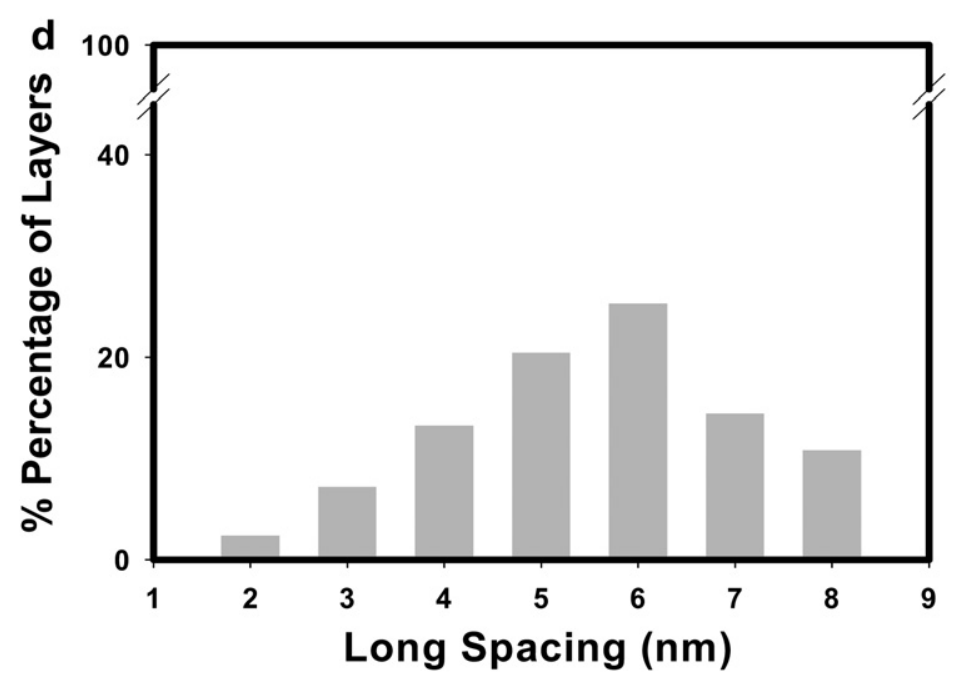

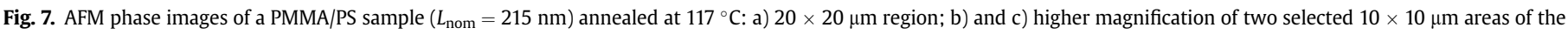
same sample; d) statistical distribution of the AFM long spacings.

the presence of any weak USAXS maxima. At still higher temperatures, in the range $130-140{ }^{\circ} \mathrm{C}$, the new domains should tend to grow in order to reduce the total interfacial energy, involving a complete rearrangement of the layers that could end up with the building of well-defined interfaces and even new layer periodicities.

A similar behaviour has been earlier described by Krausch [38], on annealing as a function of time, an artificially created 50/50 multilayer of deuterated polystyrene (dPS) and partially brominated polystyrene $\left(\mathrm{PBr}_{\mathrm{x}} \mathrm{S}\right)$. At early annealing times the initially sharp phase boundaries were shown to be smeared out; followed, in a second step, by an increase (doubling) of the layer thickness. At later times, a high degree of new layered ordering became quite clear and the new multilayered structure was proved to remain stable. These experimental results were also supported by convincing numerical simulations [38]. The same authors finally suggested that the observed behaviour could well be the characteristic way in which multilayers of incompatible polymers decay on heating above the glass transition temperature.

At even higher temperatures (above $140^{\circ} \mathrm{C}$ ), AFM results (Fig. 9) reveal the presence of a distorted globular nanostructure which is a

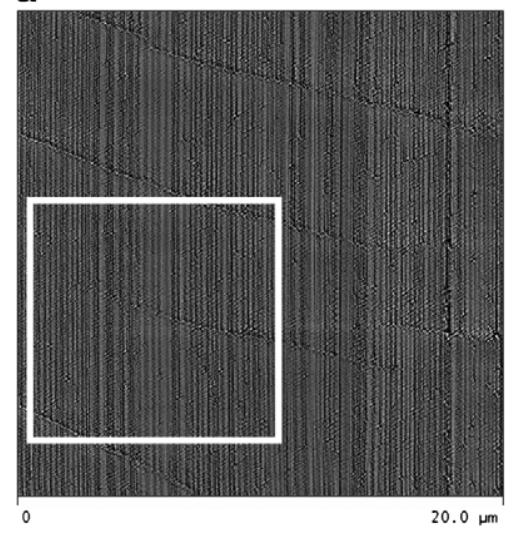

b

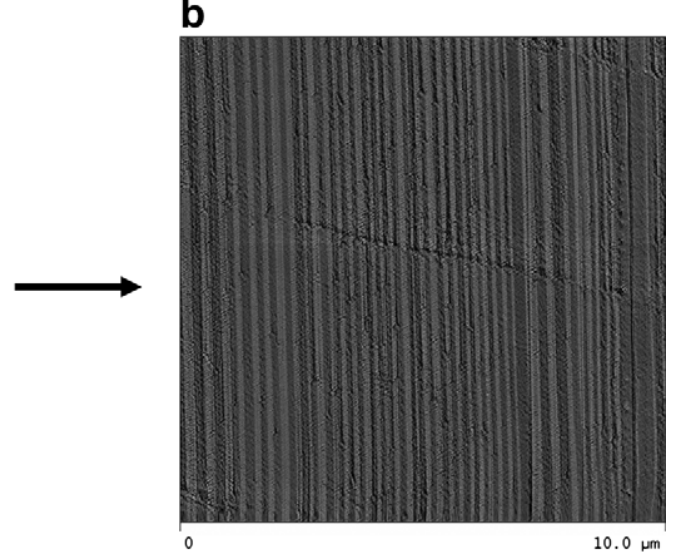

Fig. 8. AFM phase image of a PMMA/PS sample $\left(L_{\text {nom }}=215 \mathrm{~nm}\right)$ annealed at $132{ }^{\circ} \mathrm{C}$ : a) $20 \times 20 \mu \mathrm{m}$ region and b) selected $10 \times 10 \mu \mathrm{m}$ area at a higher magnification. 
a

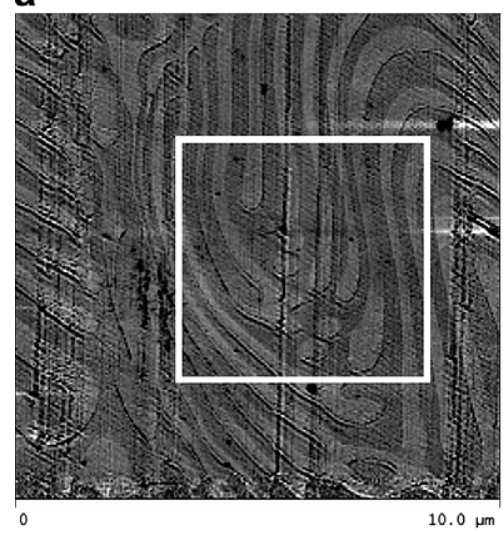

b

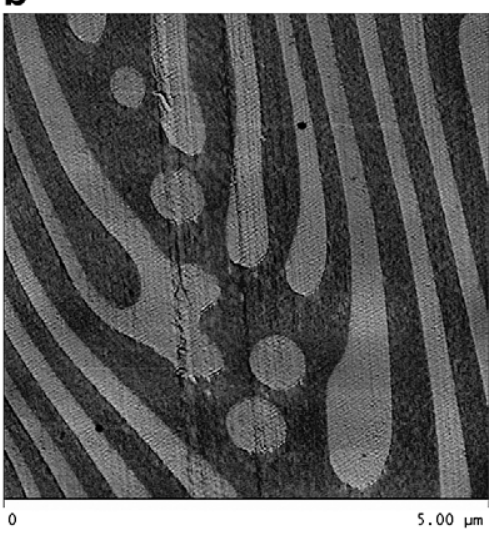

Fig. 9. AFM phase image of a PMMA/PS sample $\left(L_{\text {nom }}=215 \mathrm{~nm}\right)$ annealed at $150{ }^{\circ} \mathrm{C}$ : a) $10 \times 10 \mu \mathrm{m}$ region and b) selected $5 \times 5 \mu \mathrm{m}$ area at a higher magnification.

not anymore capable of giving rise to discrete scattering. Preceding results [37] show that, on heating up to the molten state, a forcedassembly of alternating high density polyethylene (HDPE) nanolayers and thicker layers of PS also brake up into a dispersion of HDPE nanoparticles in a PS matrix.

As a final remark, we are aware that the interpretation given to the above experimental results, obtained at room temperature, is still preliminary and future real-time USAXS experiments as a function of temperature would be of great value to test it.

\section{Conclusions}

The use of USAXS with the X-ray beam parallel to the nanolayered packing reveals the occurrence of scattering maxima corresponding to the PMMA/PS stacking periodicity for films prepared by the coextrusion method. For the first time, USAXS experiments permit the detection of the alternating architecture of amorphous polymer nanolayers with small difference in electronic density. The experimental long spacings derived from USAXS show values for the amorphous/amorphous nanolayers, which correlate well with the nominal periodicity values of the stacks. Annealing of the samples in the range RT- $140{ }^{\circ} \mathrm{C}$ mostly preserves the nanolayered structure as evidenced by AFM. However, the absence of USAXS maxima in an intermediate range of temperatures $\left(110-130{ }^{\circ} \mathrm{C}\right.$ ) could probably account for complex spinodal dewetting processes occurring between the forced-assembled polymer layers. Although some basic mechanisms have been addressed, a detailed explanation for this behaviour is still missing. Above $140{ }^{\circ} \mathrm{C}$, the interfacially driven break-up of the layers ends up with the final disappearance of the multilayered structure.

\section{Acknowledgements}

Grateful acknowledgement is due to the MEC, Spain (grant FIS2007-60534) for the support of this work. This research was also funded by the NSF Center for Layered Polymeric Systems (grant DMR-0423914) and the European Community contract RII3-CT2004-506008 (IA-SFS), DESY project II-20070031. Special thanks are due to Dr. A. Timmann (DESY-HASYLAB) for his valuable help.

\section{References}

[1] Bernal-Lara TE, Ranade A, Hiltner A, Baer E. In: Michler GH, Baltá-Calleja FJ, editors. Mechanical properties of polymers based on nanostructure and morphology. CRC Taylor \& Francis; 2005. p. 630-78.
[2] Cheng W, Gomopoulos N, Fytas G, Gorishnyy T, Walish J, Thomas EL, et al. Nanoletters 2008;8(5):1423-8.

[3] Wang H, Keum JK, Hiltner A, Baer E, Freeman B, Rozanski A, et al. Science 2009;323:757-60.

[4] Kim SH, Misner MJ, Russell TP. Adv Mater 2008;20:4851-8.

[5] Roth CB, McNerny KL, Jager WF, Torkelson JM. Macromolecules 2007;40:2568-74.

[6] Ennis D, Betz H, Ade H. J Polym Sci Part B Polym Phys 2006;44:3234-44

[7] Decher G. Science 1997;277(5330):1232-7.

[8] Ania F, Puente Orench I, Baltá-Calleja FJ, Roth S, Khariwala D, Hiltner A, et al. Macromol Chem Phys 2008;209(13):1367-73.

[9] Liu RYF, Jin Y, Hiltner A, Baer E. Macromol Rapid Commun 2003;24:943-8.

[10] Anastasiadis SH, Russell TP, Satija SK, Majkrzak CF. J Chem Phys 1990;92:5677-91.

[11] Liu RYF, Bernal-Lara TE, Hiltner A, Baer E. Macromolecules 2005;38:4819-27.

[12] Liu RYF, Bernal-Lara TE, Hiltner A, Baer E. Macromolecules 2004;37:6972-9.

[13] Roth CB, Torkelson JM. Macromolecules 2007;40:3328-36.

[14] Sharp JS, Teichroeb JH, Forrest JA. Eur Phys JE 2004;15(4):473-87.

[15] Sharp S, Forrest JA. Eur Phys JE 2003;12(Suppl. 1):S97-101.

[16] Serghei A, Hartmann L, Kremer F. J Non-Cryst Solids 2007;353 $(47-51): 4330-3$.

[17] Napolitano S, Wübbenhorst M. J Phys Chem B 2007;111(21):5775-80.

[18] Michler GH, Kausch HH, Adhikari R. J Macromol Sci B Phys 2006;45 (5):727-39.

[19] Adhikari R, Henning S, Michler GH. Macromol Symp 2006;233:26-35.

[20] Kim H, Foster MD, Jiang H, Tullis S, Bunning TJ, Majkrzak CF. Polymer 2004; $45: 3175-84$

[21] Müller-Buschbaum P. In: Stamm M, editor. Polymer surfaces and interfaces: characterization, modification and applications. Berlin: Springer; 2008. p. 17-46.

[22] Craster RV, Matar OQ. Rev Mod Phys 2009;81:1131-98.

[23] Seemann R, Herminghaus S, Jacobs K. J Phys Condens Matter 2001;13:4925-38.

[24] Konnur R, Kargupta K, Sharma A. Phys Rev Lett 2000;84:931-4.

[25] Becker J, Grün G, Seemann R, Mantz H, Jacobs K, Mecke KR, et al. Nat Mater 2003;2:59-63.

[26] Ade H, Winesett DA, Smith AP, Qu S, Ge S, Sokolov J, et al. Europhys Lett 1999;45(4):526-32.

[27] Wang C, Krausch G, Geoghegan M. Langmuir 2001;17:6269-74.

[28] de Silva JP, Geoghegan M, Higgins AM, Krausch G, David M-O, Reiter G. Phys Rev Lett 2007;98:267802.

[29] Xue L, Hu B, Han Y. J Chem Phys 2008;129:214902.

[30] Baer E, Kerns J, Hiltner A. In: Cunha A, Fakirov S, editors. Structure development during polymer processing. Dordrecht: Kluwer Academic Publishers; 2000. p. $327-44$.

[31] Ivan'kova EM, Michler GH, Hiltner A, Baer E. Macromol Mater Eng 2004;289 (9):787-92.

[32] Bernal-Lara TE, Liu RYF, Hiltner A, Baer E. Polymer 2005;46:3043-55.

[33] Wang F, Saeki S, Yamaguchi T. Polymer 1997;38(14):3485-92.

[34] Wippler C. Polym Bull 1991;25:357-63.

[35] Reiter G, Hamieh M, Damman P, Sclavons S, Gabriele S, Vilmin T, et al. Nat Mater 2005;4:754-8.

[36] Stribeck N. X-ray scattering of soft matter. Berlin: Springer-Verlag; 2007. pp. 117-27.

[37] Jin Y, Hiltner A, Baer E, Masirek R, Piorkowska E, Galeski A. J Polym Sci Part B Polym Phys 2006;44:1795-803.

[38] Krausch G, Mlynek J, Straub W, Brenn R, Marko JF. Europhys Lett 1994;28 (5):323-8. 